\title{
Vietnamese focus particles and derivation by phase
}

\author{
Michael Yoshitaka Erlewine ${ }^{1}$
}

Received: 31 March 2015 / Accepted: 8 December 2016 / Published online: 31 May 2017

(C) The Author(s) 2017. This article is an open access publication

\begin{abstract}
I show that the focus-sensitive operator chi 'only' in Vietnamese is a sentential modifier and required to be as low as possible in its phase while taking its focus associate in its scope. I show that this "as low as possible" requirement cannot be violated even in order to yield a different meaning. Within a phase-based, bottomup conception of structure-building, I analyze this behavior as the result of sentential focus particles adjoining as early as possible while being interpretable. The fact that this requirement only holds between different adjunction positions in each phase is naturally explained by the theory of derivation by phase (Chomsky 2000, 2001) and provides a new kind of evidence for this form of cyclic structure-building. This work also provides cross-linguistic support for one aspect of the controversial analysis of German focus particles as sentential modifiers (Jacobs 1983, 1986; Büring and Hartmann 2001), which similarly requires an "as low as possible" requirement on sentential focus particles.
\end{abstract}

Keywords Vietnamese - Association with focus - Sentential only . Adverb placement $\cdot$ Phases

\section{Introduction}

This paper describes the distribution of the focus-sensitive 'only' particle chi in Vietnamese, as in (1). We say that chi is "focus-sensitive" because the meaning introduced by $c h i$ depends on the placement of focus, indicated by capital letters

\footnotetext{
$\bowtie \quad$ Michael Yoshitaka Erlewine mitcho@nus.edu.sg

1 Department of English Language and Literature, National University of Singapore, 7 Arts Link Block AS5, Singapore 117570, Singapore
} 
below, elsewhere in the utterance. The focus-sensitivity of $c h i$ parallels the familiar behavior of English only, as reflected in the translations in (1).

(1) Chi 'only' is focus-sensitive:

a. Nam chỉ MUA cuốn sách.

Nam ONLY buy CL book

'Nam only BOUGHT the book.'

$\Rightarrow$ Nam didn't do anything else with the book (e.g. read it).

b. Nam chỉ mua cuốn SÁCH.

Nam ONLY buy CL book

'Nam only bought the BOOK.'

$\Rightarrow$ Nam didn't buy anything else (e.g. the magazine).

Focus-sensitive operators such as chi quantify over a set of alternative propositions, and the placement of focus contributes to the computation of these alternatives (Rooth 1985, a.o.). This compositional semantics of focus leads to the requirement that the focused constituent must be in the scope of the focus-sensitive operator. Structurally speaking, the semantics then predicts that sentential focus particles should be able to associate with any constituent that they c-command.

This prediction seems to not hold in the general case. I will show that $c h i$ is a sentential modifier that can be adjoined at various points on the clausal spine (Hole 2013), for example above the subject (2). From this position, chi takes the subject in its scope and is able to associate with it (2a). However, from this high position in the clause chi is unable to associate with the constituents 'buy' and 'the book' as was possible when $c h i$ was preverbal (1), even though $c h i$ still c-commands these constituents in $(2 \mathrm{~b}-\mathrm{c})$.

(2) Pre-subject chi cannot associate with foci in the verb phrase:

a. Chỉ NAM mua cuốn sách. ONLY Nam buy CL book

'Only NAM bought the book.'

$\Rightarrow$ No one else bought the book.

b. * Chỉ Nam MUA cuốn sách. ONLY Nam buy CL book

Intended: 'Nam only BOUGHT the book.' (=1a)

c. * Chỉ Nam mua cuốn SÁCH. ONLY Nam buy CL book

Intended: 'Nam only bought the BOOK.' (=1b)

On the surface, an attractive alternative explanation for the contrasts in (1-2) would be to say that chi in (2) is a so-called constituent 'only,' adjoined directly to the subject Nam, and therefore does not c-command the intended associate in (2b, c). However, I will argue in Sect. 2, below, that chi is uniformly a sentential modifier, 
as described in Hole (2013). The inability of a higher chi to associate with a lower focus as in $(2 b, c)$ then requires an alternative explanation.

I propose that contrasts such as in (2) are the result of a requirement that focussensitive operators be adjoined as low as possible while satisfying the semantic requirement to take their focus associate in their scope. In other words, examples $(2 \mathrm{~b}, \mathrm{c})$ are "blocked" by the availability of $(1 \mathrm{a}, \mathrm{b})$, respectively, which yield the desired focus association with chi adjoined in a lower position in the clause. The grammaticality of (2a) reflects the fact that a lower position of chi, in preverbal position, would not be interpretable with $c h i$ associating with the intended subject associate.

Further study of the distribution of chi will show that this "as low as possible" requirement is relativized to each phase. I propose to analyze the effects of this requirement as the reflection of a syntactic constraint for focus-sensitive operators to be adjoined as early as possible in their phase. The fact that this requirement is relativized to each phase reflects the cyclic nature of syntactic structure-building, e.g. derivation by phase (Chomsky 2000, 2001). I will also show that this behavior cannot be explained as a semantically-sensitive process by which chi must be as low as possible unless a higher attachment yields a different semantic interpretation (cf Fox 1995, 2000).

By documenting this "as low as possible" behavior of sentential focus particles in Vietnamese, this paper will also indirectly contribute to an ongoing debate regarding the analysis of German focus-sensitive particles. For reasons specific to German syntax, it is difficult to determine conclusively whether focus-sensitive operators in German are sentential modifiers or sub-sentential constituent modifiers. Jacobs (1983, 1986) and Büring and Hartmann (2001) make the strong but controversial claim that all German focus-sensitive operators are sentential modifiers. This sentential-only approach requires proposing a requirement that focus particles be as low as possible, akin to what I show here for Vietnamese. This constraint has been strongly questioned by critics on conceptual grounds, including Reis (2005) who calls it "spurious" and "more than doubtful." The work here thus contributes to this debate by showing that a grammatical process by which sentential focus particles are placed as low as possible is independently motivated in the genetically unrelated language of Vietnamese.

I will begin in Sect. 2 by introducing some relevant background on focus particle syntax and two 'only' particles in Vietnamese. I will argue that the particle of interest, chi, is uniformly a sentential modifier, as it has been previously described by Hole (2013). In Sect. 2.2, I will present the "as low as possible" distribution of chi in Vietnamese. I will also present my argument that this behavior cannot be the result of a semantically-sensitive constraint which would allow focus particles to be adjoined in a higher position if a different meaning is derived. Finally, in Sect. 4, I will present my formal proposal. I show that the fact that the "as low as possible" requirement is relativized to the phase forms a new type of argument for the cyclic nature of syntactic structure-building (Chomsky 2001). I conclude in Sect. 5 with a discussion of the relation of the findings here to the broader debate on constraints on the placement of focus particles cross-linguistically. 


\section{Classifying focus particles}

In this section I will discuss the syntactic classification of focus-sensitive particles into sentential and constituent-modifying operators. I then discuss the two 'only' particles in Vietnamese of interest here, $c h i$ and mối. The goal of this section is to motivate the view that chi is a sentential 'only,' in contrast to the constituent 'only' môi (Hole 2013). This will lay the groundwork for the investigation of the structural distribution of chi in Sect. 3.

\subsection{Two types of focus particles}

Focus-sensitive operators can take different syntactic forms. The literature on focus association draws a first-order distinction between focus particles which adjoin to the clausal spine and those which adjoin to non-clausal constituents. In a parallel to the dichotomy between sentential negation and constituent negation, I refer to these two types of focus particles as sentential and constituent focus particles. ${ }^{1}$

For example, the focus particle only in English is ambiguous between a sentential focus particle and a constituent focus particle, which are homophonous. The two uses are demonstrated in (3), where the two variants have equivalent truth conditions. Following Jackendoff (1972), here I will use F-marking to indicate the position of focus, abstracting away from its detailed phonetic realization.

\section{(3) English sentential and constituent only:}

a. Nam only likes $[\mathrm{Ngan}]_{\mathrm{F}}$.

sentential only

b. Nam likes only $[\mathrm{Ngan}]_{\mathrm{F}}$.

constituent only

Further investigation shows that these two onlys behave differently. Most notably, sentential only always takes scope in its pronounced position (4), whereas constituent only can lead to scope ambiguities (5). See Taglicht (1984), Rooth (1985, chapter 3), and Bayer (1996) for discussion of such contrasts.

\footnotetext{
1 A note on terminology is in order here. In much previous literature, these two categories have been called adverbial vs adnominal focus particles (see e.g. Büring and Hartmann 2001), which I have resisted in my work as constituent particles can adjoin to non-nominal constituents such as PPs. Hole (2013) uses the terms adverbial vs adfocus, but focus particles can adjoin to focus-containing phrases, not necessarily directly to focused constituents (i.e. they can pied-pipe). In my own previous work I have used adverbial vs constituent-marking for this distinction. However, an anonymous $J E A L$ reviewer rightly notes that the term adverb can be used to describe modifiers in positions other than the clausal spine as well, making all adverbial vs other classifications potentially misleading. This reviewer suggested the sentential vs constituent terminology, in a parallel with negative particles. I adopt this suggestion here with enormous gratitude.

This parallel between focus-sensitive operators and negation, as well as other logical operators such as conjunction, is unsurprising from the perspective of their semantics: the classic focus-sensitive operators of only, even, and also all ultimately quantify over propositions in their semantics, just as negation and coordination do. See Chapter 3 of Rooth (1985) for relevant discussion of the relation between sentential and constituent variants of logical operators.
} 
(4) Sentential focus particles take surface scope: (based on Taglicht 1984, 150)

a. They were advised to only learn $[\text { Spanish }]_{F}$. advised $>$ only

b. They were only advised to learn $[\text { Spanish }]_{F}$. only $>$ advised

(5) Constituent focus particles can lead to scope ambiguities: (Taglicht 1984, 150) They were advised to learn only [Spanish $]_{\mathrm{F}} . \quad \checkmark$ advised $>$ only, ${ }^{\checkmark}$ only $>$ advised

This dichotomy between sentential and constituent focus particles is further supported by the fact that some particles only take one form or the other: for example, English also is unambiguously a sentential modifier, even though only and even are ambiguous between sentential and constituent uses. ${ }^{2}$ However, by far the best motivation for this distinction between sentential and constituent focus particles is the fact that some languages lexicalize them differently, as we will see in Vietnamese.

Next, I turn to the structural relationship between these two types of focus particles and the focused constituents that they associate with, which I will also call their focus associates. Both sentential and constituent focus particles follow the c-command requirement in (6):

(6) The c-command requirement on association with focus: (Jackendoff 1972; Rooth 1985; Tancredi 1990; Aoun and Li 1993; McCawley 1996; Bayer 1996, a.o.) A focus-sensitive operator must c-command its associate.

To see the effects of this requirement, consider the data in (7):

(7) Patterns of association with only: (based on McCawley 1996, 172)

a. i. John only put [salt $]_{F}$ on the potatoes.

ii. John only put salt on [the potatoes $]_{\mathrm{F}}$.

iii. $*\left[\mathrm{John}_{\mathrm{F}}\right.$ only put salt on the potatoes. ${ }^{3}$

b. i. John put only [salt $]_{F}$ on the potatoes.

ii. * John put only salt on [the potatoes $]_{\mathrm{F}}$.

iii. John put salt only on [the potatoes $]_{F}$.

iv. John put salt on only [the potatoes]F.

The preverbal only in (7a) is able to associate with any postverbal choice of focus, whereas only in a postverbal position (7b) must associate with a focus in the constituent immediately following it. This pattern is explained by the generalization that focus-sensitive operators must c-command their focus associates (6), together with different adjunction positions for only. Only in (7a) is a sentential only, adjoined to

\footnotetext{
2 But see Wagner (2013) for a proposal that English sentential even and constituent even differ in their semantics, supporting the view that these are two homophonous particles.

3 Jackendoff (1972) notes that the configuration in (7aiii) is however grammatical with even, and it is also grammatical with also (Krifka 1998, a.o.). Erlewine (2014) argues that this is a systematic difference between different focus-sensitive operators based on their semantics: even and also can associate with focused material which has moved out of their scope, while only cannot. Association with non-exclusive particles therefore systematically allows certain superficial exceptions to the c-command requirement in (6). Discussion in this paper will therefore concentrate on exclusive particles such as 'only' which do obey this strict c-command requirement.
} 
VP and therefore c-commanding all of the material within the VP. ${ }^{4}$ The onlys in (7b) are constituent onlys, narrowly adjoined to DP or PP constituents, and therefore must associate with a focus within these constituents.

This generalization in (6) has been argued to follow from the compositional semantics of focus association itself, as in the work of Rooth $(1985,1992)$. Here I will simply adopt this well-established structural requirement in (6) as a descriptive generalization, without presenting its theoretical motivation. ${ }^{5}$

The c-command requirement (6) and patterns of association as in (7) can be an important clue for analyzing a particular focus particle as a sentential or constituent modifier. Consider the case of English pre-subject only, as in (8).

(8) Two parses for English pre-subject only:

Only [the Queen] $\mathrm{F}$ can be depicted on currency.

a. [TP only [TP [the Queen $]_{\mathrm{F}}$ can be depicted on currency]] sentential only

b. [DP only [DP the Queen $]_{F}$ ] can be depicted on currency constituent only

Because the focused constituent the Queen is preverbal, only in (8) could conceivably be a sentential only adjoined to the entire clause or a constituent only adjoined narrowly to the subject. In both cases, only will satisfy the c-command requirement on focus association. However, notice that a pre-subject only as in (8) is unable to associate with a focus that follows the subject, as seen in (9).

(9) Limited association with pre-subject only:

* Only the Queen can be depicted on [currency $]_{F}$.

This requirement for pre-subject only to associate with (a part of) the subject suggests that English pre-subject only is a constituent only as in (8b), and that sentential only cannot adjoin to TP as in (8a). ${ }^{6}$ As we will see later with Vietnamese, however, evidence of this form is not necessarily conclusive: we might have good reason to believe that a particle is a sentential modifier and nonetheless observe such a restricted pattern of focus association.

\subsection{Two 'only's in Vietnamese}

Vietnamese has a morphologically rich system of focus-sensitive operators. Various operators in Vietnamese with even, also, and only semantics, in different configurations, are described in detail in Hole (2013). Here I will concentrate on two 'only' particles described there, $c h i$ and $m \tilde{\hat{o} i}{ }^{7}$

\footnotetext{
4 Throughout this paper, I will not distinguish between the constituents $v \mathrm{P}$ and VP, using the label VP throughout. See also footnote 22.

5 In addition to Rooth's original work, for textbook-style introductions to focus semantics and Rooth's Alternative Semantics framework, see Part 3 of Kadmon (2001) and Chapter 4 of Beaver and Clark (2008).

6 In the case of English, there is independent evidence that pre-subject only is a constituent only, because it can take wide scope, in a higher clause, under certain circumstances; cf (4-5). See Bayer (1996, 59-60) for such evidence.

7 I limit attention here to exclusive focus particles, as non-exclusive focus particles are systematically less strict in their surface c-command requirement. See footnote 3 above.
} 
Hole (2013) argues that chi is a sentential 'only,' whereas mối is a constituent 'only.' A sentence with a given focus can have one, the other, or both, to yield the same meaning. ${ }^{8,9}$ An example is given in (10) below. In this example, with a postverbal focus, chi is adjoined in a preverbal position on the clausal spine whereas the constituent modifier $m \tilde{\hat{i}} i$ is adjoined directly to the focus. I gloss the sentential 'only' chi as $\mathrm{ONLY}_{\text {sent }}$ and the constituent 'only' mối as ONLY ${ }_{\text {cons }}$.

(10) Two 'only's in Vietnamese:
a. Nam chỉ mua [cuốn sách $]_{F}$. Nam ONLY $_{\text {sent }}$ buy CL book
b. Nam mua mối [cuốn sách $]_{F}$. Nam buy ONLY cons CL book
c. Nam chỉ mua mỗi [cuốn sách $]_{\mathrm{F}}$. Nam ONLY sent buy ONLY cons $_{\text {CL book }}$
'Nam only bought [the book $]_{F} . ' \quad(a=b=c)$

A range of contrasts support the idea that chi is a sentential 'only' and mối is a constituent 'only.' Consider the examples in (11) below with a preverbal locative PP adjunct 'at school.' For 'only' to associate with 'school,' it must be outside of the PP on the clausal spine (11a), rather than inside the PP (11b). In contrast, the constituent 'only' $m$ ô $i$ is naturally adjoined directly to the focused constituent, inside the PP (11c).

(11) 'Only' associating into a preverbal PP:
a. Tôi chỉ [ [PP ở [trường $\left.]_{\mathrm{F}}\right]$ học Tiếng Anh].
I $\mathrm{ONLY}_{\text {sent }}$ at school study English
b. * Tôi [PP ở chỉ [trường $\left.]_{\mathrm{F}}\right]$ học Tiếng Anh.
I at ONLY sent $_{\text {school study English }}$
c. Tôi [PP ở mối [trường $\left.]_{F}\right]$ học Tiếng Anh.
I at ONLY cons school study English
'I only study English at $[\text { school }]_{F}$.'

$(\mathrm{a}=\mathrm{c})$

Further evidence comes from the relative ordering of the two 'only' particles. Consider the examples in (12), which illustrate different options for subject focus with 'only.' When both $c h i$ and $m \tilde{\hat{i}} i$ co-occur, they must be in chi-mối order (12c), and the reverse $m \tilde{\hat{i}} i$-chi order is ungrammatical $(12 \mathrm{~d})$.

\footnotetext{
Footnote 7 continued

Some examples here will also have a preverbal mới (not to be confused with $\mathrm{ONLY}_{\text {cons }}$, which is môi $)$ and clause-final thôi. I gloss both as PRT here. For mới, see Nguyen (2013); Hole (2013). For thôi, see Hole (2014).

8 The case of both 'only' operators co-occurring to yield one semantic invocation of exclusive semantics, in (10c), must be thought of as a type of concord process. I will leave open the question of the compositional semantics of such examples.

9 See Jannedy (2007) for a description of the prosodic correlates of F-marking in Vietnamese.
} 
(12) 'Only' associating with the subject:
a. $\checkmark$ Mối $[\mathrm{Nam}]_{\mathrm{F}}$ mua cuốn sách.
b. $\checkmark$ Chi $[\mathrm{Nam}]_{\mathrm{F}} \ldots$ ONLY $_{\text {cons }}$ Nam buy CL book
ONLY $_{\text {sent }}$ Nam
$\begin{array}{lll}\text { c. } \checkmark \text { Chỉ mối } & {[\mathrm{Nam}]_{\mathrm{F}} \ldots} \\ \text { ONLY }_{\text {sent }} & \text { ONLY }_{\text {cons }} & \mathrm{Nam}\end{array}$

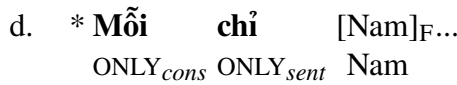

'Only $[\mathrm{Nam}]_{\mathrm{F}}$ bought the book.'

This is predicted by the view that chi is a sentential 'only' on the clausal spine and $m \tilde{o} i$ is a constituent 'only' adjoined directly to the subject DP, as schematized in (13) below. The sentential 'only' will necessarily be linearized outside of the constituent 'only.'

\section{(13) The structure of (12c):}

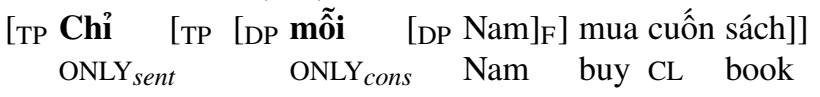

A reviewer notes that $c h i$ can sometimes appear in utterances between a verb and its object, which is unexpected under the analysis here of chi as a sentential 'only' which always adjoins to the clausal spine above VP. An example is (14) below.

(14) Sentential 'only' chi in postverbal position:

Tôi đọc *(\#) chỉ (có) cuốn sách [này] $]_{F}$.
I read ONLY sent have CL book this 'I only read [this] $]_{\mathrm{F}}$ book.'

However, two aspects of such examples suggest that they are not true counterexamples to the idea that $c h i$ is unambiguously a sentential 'only.' First, the postverbal $c h i$ must be introduced by a pause, indicated by \# above, which is not regularly required between verbs and objects in Vietnamese. Second, postverbal chi is optionally followed by the existential 'have' verb có. Note that chi in regular preverbal position cannot regularly be followed by có, as seen in example (15): ${ }^{10}$

(15) Existential có cannot be added to regular preverbal $c h i$ :

Tôi chỉ (*có) đọc cuốn sách [này $]_{\mathrm{F}}$.

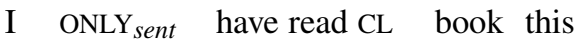

'I only read [this] $]_{\mathrm{F}}$ book.'

I propose that (14) is instead a biclausal utterance, with a pro-dropped object of 'read' which is then described as being a specific book and not others. It is in fact possible to include an overt pronoun in the object position, as in (16), which is then clearly two indepedent clauses. I argue that (14) above is simply a version of (16) with a pro-dropped object. ${ }^{11}$

\footnotetext{
10 In addition to being an existential main verb, có has a number of uses as a functional morpheme. For example, Trinh (2005) argues that có in some cases is a default realization of T, akin to do-support. My argument here does not depend on the precise function of có in (14) and (16). What is important is that the availability of có reveals the presence of additional clausal structure in (14), in contrast to regular uses of chỉ where có cannot occur (15).

11 An alternative approach may be to say that (14) is an "amalgam" in the sense of Lakoff (1974) and subsequent work (see e.g. Guimarães 2004; Kluck 2011). Two examples from Lakoff (1974) are reproduced
} 


\section{(16) The overt biclausal source for (16):}

Tôi đọc nó. Chỉ (có) cuốn sách $[\text { này }]_{F}$.

I read it ONLY $_{\text {sent }}$ have CL book this

literally: 'I read it. Only [this $]_{F}$ book.'

Evidence for this biclausal analysis of example (14) comes from the scope of chi in postverbal position as in (14). As noted above-see (4) - sentential focus particles take scope in their pronounced position. This can be shown independently for Vietnamese $c h i$, for example in (17a-b) below. In (17a), chi precedes negation and 'only' unambiguously scopes over negation. In contrast, in (17b), chi follows the negation and 'only' must scope under negation.

(17) Sentential 'only' $c h i$ takes surface scope with respect to negation: ${ }^{12}$

a. chi NEG:

$$
{ }^{\mathrm{ONLY}}>\mathrm{NEG},{ }^{*} \mathrm{NEG}>\mathrm{ONLY}
$$

Tôi chỉ không đọc cuốn sách [này $]_{\mathrm{F}}$.

I ONLY $_{\text {sent }}$ NEG read CL book this

'I only didn't read [this] $]_{F}$ book.' $\Rightarrow$ I read all other books.

b. NEG $c h i$ :

$*^{\mathrm{ONLY}}>\mathrm{NEG},{ }^{\checkmark} \mathrm{NEG}>\mathrm{ONLY}$

Tôi không chỉ đọc cuốn sách [này $]_{\mathrm{F}}$.

I NEG ONLY $_{\text {sent }}$ read CL book this

'I didn't only read [this $]_{F}$ book.' $\Rightarrow$ I read (some) other books as well.

Now consider an example with a postverbal chi as in (14) above, but with a negation preceding the verb 'read': example (18) below. This example is interpreted unambiguously with 'only' taking wide scope above the negation.

\section{(18) Postverbal chi as in (14) takes obligatory wide scope:}

Tôi không đọc *(\#) chỉ (có) cuốn sách [này $]_{\mathrm{F}}$.

I NEG read ONLY $_{\text {sent }}$ have CL book this

$\checkmark$ 'I only didn't read [this] $]_{\mathrm{F}}$ book.' $\Rightarrow$ I read all others. $\quad{ }^{\text {ONLY }}>$ NEG $(=17 \mathrm{a})$

* 'I didn't only read [this $]_{\mathrm{F}}$ book.' $\Rightarrow$ I read some others. $*_{\mathrm{NEG}}>\mathrm{ONLY}(=17 \mathrm{~b})$

\section{Footnote 11 continued}

in (i) and (ii) below with my paraphrases. Lakoff attributes the observation of examples such as (i) to Avery Andrews, by way of Háj Ross, and (ii) to Larry Horn.

(i) John invited [you'll never guess how many people] to his party.

'John invited some people to his party; you'll never guess how many (people).'

(ii) John is going to, [I think it's Chicago] on Saturday.

'John is going someplace on Saturday; I think it's Chicago.'

In contrast to Vietnamese, English does not allow pro-drop, making it clear that such utterances involve some sort of embedding of the material in brackets in (i-ii), which acts as a comment on the argument interpreted in that position.

12 At first glance, the variable position of $c h i$ with respect to negation in (17) may seem to go against the generalization I intend to motivate in the following section, that chi must be as low as possible in its phase. I will return to this case below, where I appeal to the fact that the Vietnamese negator khong is not an adjunct but a verb (Trinh 2005). 
This result is surprising if (18) is monoclausal with chi structurally below the negation, as the word order seems to indicate, given that chi takes surface scope with respect to negation in (17) above. Instead, my analysis where chi is part of an independent clause, describing the object of the preceding clause-what was not read-predicts that 'only' will necessarily take scope above negation, as observed.

Note furthermore that the biclausal utterance in (19) - a variant of (18) with an overt pronoun in object position-is also interpreted together with 'only' scoping unambiguously over the negation.

(19) Biclausal utterance explains wide scope of $c h i$ in (18):

Tôi không đọc nó. Chỉ (có) cuốn sách [này]F.

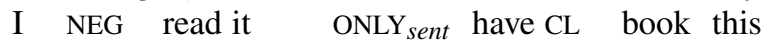

literally: 'I didn't read it. Only [this] $]_{F}$ book.'

$\checkmark$ 'I only didn't read [this] $]_{F}$ book.' $\Rightarrow$ I read all others. $\quad{ }^{\text {ONLY }}>$ NEG $(=17 \mathrm{a})$

* 'I didn't only read [this] $]_{\mathrm{F}}$ book.' $\Rightarrow$ I read some others. *NEG > ONLY $(=17 \mathrm{~b})$

The superficial availability of chi (có) in postverbal position as in $(14,18)$ is thus shown to be an illusion. The distribution of chi observed above shows that $c h i$ is consistently a sentential 'only' in Vietnamese. At the same time, we saw that chi can be adjoined at different heights on the clausal spine, in immediately preverbal position (10), above a preverbal PP adjunct (11a), or even above the subject (12). I will now take a closer look at this distribution of chi.

\section{The distribution of sentential 'only' chi'}

In this section I will document where the sentential 'only' chi can be placed and what it then can associate with. The data I present will motivate the following empirical generalization:

\section{(20) Generalization:}

Sentential focus particles (focus-sensitive sentential modifiers) must be as low as possible while c-commanding their focus associate, within a given phase.

A similar requirement that sentential focus particles must be as low as possible has been independently proposed previously for German by Jacobs $(1983,1986)$ and Büring and Hartmann (2001), who advocate for the strong position that all German focus particles are sentential modifiers. However, this position has been very controversial for German (see e.g. Reis 2005; Meyer and Sauerland 2009; Smeets and Wagner 2016). I will discuss this debate over German focus particles and the relation of the findings here at the conclusion of the paper.

I will begin with the placement of $c h i$ in a simplex clause, using the baseline in (21), which includes the temporal adjunct 'yesterday' in its unmarked word order. The clausal spine of (21) is formed of two phases (Chomsky 2001). As noted in footnote 4 above, I do not distinguish between the traditional categories $v \mathrm{P}$ and VP here and will use the label "VP" for the lower phase of clauses. 


\section{(21) Baseline: “Adjunct S V O” order}

[CP Hôm qua Nam [vp mua cuốn sách. yesterday Nam buy CL book

'Nam bought the book yesterday.'

There are three possible positions for the sentential 'only' chi to adjoin in (21): immediately preverbally (adjoining to VP), immediately preceding the subject (adjoining to TP), or clause-initially (adjoining to TP, above the adjunction of 'yesterday'). ${ }^{13}$ All three of these positions for chi involve adjunction within the construction of $\mathrm{CP}$, the higher clausal phase.

In the following data, I place the sentential 'only' operator chi in these different structural positions and present the possible readings for each string. The position of F-marking required for the different readings, which is realized prosodically, is reflected only in the translations. I begin with chi in immediately preverbal position:

\section{“Adjunct S ONLY V O":}

Hôm qua Nam chỉ mua cuốn sách (thôi). yesterday Nam ONLY $_{\text {sent }}$ buy CL book PRT
a. $\checkmark$ 'Nam only bought [the book $]_{\mathrm{F}}$ yesterday.'
b. $\quad \checkmark$ 'Nam only [bought $]_{\mathrm{F}}$ the book yesterday.'
c. $\checkmark$ 'Nam only [bought the book] $]_{F}$ yesterday.'
d. * 'Only [Nam $]_{\mathrm{F}}$ bought the book yesterday.'
e. * 'Nam only bought the book [yesterday $]_{F}$.'
f. * 'It's only that [Nam bought the book yesterday $]_{\mathrm{F}}$.'

With chi in immediately preverbal position (22), 'only' can associate with the verb, the object, or the entire VP-in other words, any constituent that it c-commands. As expected, 'only' cannot associate with the subject Nam or the temporal adjunct 'yesterday,' which are not c-commanded by 'only.'

Now consider higher placements of chi. In (23), chi immediately precedes the subject Nam, and is required to associate with it. This is surprising in light of my arguments in the previous section that $c h i$ is a sentential 'only, adjoining to the clausal spine. From this position, chi in (23) is predicted to c-command the VP as well, but the VP and its subconstituents are not valid choices of focus for this example.

\section{“Adjunct ONLY S V O”:}

Hôm qua chỉ Nam (mới) mua cuốn sách (thôi).

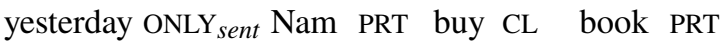

\footnotetext{
13 I assume adjunction is to maximal projections. In particular, adjunction to the T' bar-level is prohibited. This immediately explains the ungrammaticality of $c h i$ adjoined between the subject and the future marker $s \tilde{e}$ and anterior marker $\tilde{a}$, as observed by Hole (2013) and an anonymous reviewer, because these markers realize the head T (Trinh 2005). The clause-initial adjunction of chi (23) is to TP, because chi in this position follows embedding complementizers.
} 

a. * 'Nam only bought [the book]F yesterday.'
b. * 'Nam only [bought $]_{\mathrm{F}}$ the book yesterday.'
c. * 'Nam only [bought the book] $]_{\mathrm{F}}$ yesterday.'
d. $\checkmark$ 'Only [Nam $]_{\mathrm{F}}$ bought the book yesterday.'
e. * 'Nam only bought the book [yesterday $]_{\mathrm{F}}$.'
f. * 'It's only that [Nam bought the book yesterday $]_{\mathrm{F}}$.'

Similarly, consider example (24) where $c h i$ is in clause-initial position. Now $c h i$ must associate with the temporal adjunct 'yesterday' that it immediately precedes, or the entire proposition. Like (23), it is not the case that chi is able to associate with any constituent in its scope.

\section{“ONLY Adjunct S V O”:}

Chỉ hôm qua Nam (mới) mua cuốn sách (thôi).

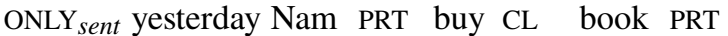
a. * 'Nam only bought [the book $]_{\mathrm{F}}$ yesterday.'
b. * 'Nam only [bought $]_{\mathrm{F}}$ the book yesterday.'
c. * 'Nam only [bought the book] $]_{\mathrm{F}}$ yesterday.'
d. * 'Only $[\mathrm{Nam}]_{\mathrm{F}}$ bought the book yesterday.'
e. $\quad \checkmark$ 'Nam only bought the book [yesterday]F.'
f. $\quad \checkmark$ 'It's only that [Nam bought the book yesterday $]_{F}$.'

Given that $c h i$ is a sentential 'only' adjoining to the clausal spine, as argued in the previous section, the unavailability of certain readings in (23-24) becomes unexpected. Specifically, the compositional semantics of focus should allow for chi to associate with any constituent in its scope, including the readings in $(23 \mathrm{a}-\mathrm{c})$ and $(24 a-d)$, contrary to fact. These contrasts in (22-24) motivate a requirement that chi must be as low as possible while c-commanding its focus associate, as in the generalization in (20) above.

As mentioned above, the three positions of $c h i$ in the simplex clause above in (2224) are all in the same phase, the higher phase of the clausal spine (the CP in (21)). Therefore, for any choice of F-marking, there is only one grammatical placement of $c h i$ : an interpretable lower adjunction position for $c h i$ blocks all higher adjunction.

This situation changes with complex clauses with additional phases where chi can be adjoined. Consider for example (25): here, I have fixed the placement of Fmarking on the embedded object Ngân. The sentential 'only' could be adjoined in the higher clause (25a) or the lower clause (25b).

\section{(25) Matrix and embedded positions for $c h i$, given embedded focus:}

a. Tôi chỉ nói [cP là Nam thích $[\mathrm{Ngân}]_{\mathrm{F}}$ (thôi).

I ONLY sent say that Nam like Ngan PRT

'I only said Nam likes [Ngan $]_{F}$.' 


\section{b. Tôi nói [CP là Nam chỉ thích $[\mathrm{Ngân}]_{\mathrm{F}}$ (thôi). I say that Nam ONLY sent like Ngan PRT 'I said Nam only likes $[\mathrm{Ngan}]_{\mathrm{F}}$.'}

Note that it is not simply the case that the placement of $c h i$ is not subject to the "as low as possible" requirement (20) in (25). For example, chi cannot be in a higher position in the matrix clause and associate with the intended associate in the embedded clause (26). The placement of chi in (26) is blocked by the "as low as possible" requirement (20) given the availability of chi in a lower position in the same phase, the matrix $\mathrm{CP}$, as in (25a).

$$
\begin{aligned}
& \text { * Chỉ tôi nói [CP là Nam thích }[\mathrm{Ngân}]_{\mathrm{F}} \text { (thôi). } \\
& \text { ONLY sent I say that Nam like Ngan PRT } \text { Intended: 'I only said Nam likes }[\mathrm{Ngan}]_{\mathrm{F}} \text { '. (=25a) }
\end{aligned}
$$

These examples show that the "as low as possible" requirement is still active for complex clauses but is not evaluated across the entire utterance. In particular, we learn from the examples in (25) that the availability of adjoining chi in an embedded CP does not block the adjunction of $c h i$ in a higher CP. The "as low as possible" requirement must be relativized to syntactic domains of particular size.

We can further motivate that the requirement is relativized to each phase, not simply each CP, based on data such as (27), repeated from (17) above. Here it is important that the sentential negator không is a verb which itself selects for a VP (Trinh 2005), but không does not embed a full CP. The availability of chi above or below không given a fixed choice of F-marking on the embedded object contrasts from what we saw above in the simplex clauses (22-24). The introduction of this additional phase boundary allows for this variable placement of chi.

\section{Sentential 'only' chi above or below the negative verb không, from (17):}

a. Tôi chỉ [VP không [VP đọc cuốn sách [này $]_{F}$.

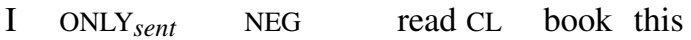

'I only didn't read [this] $]_{F}$ book.' $\Rightarrow$ I read all other books.

b. Tôi [vP không chỉ [VP đọc cuốn sách [này $]_{F}$.

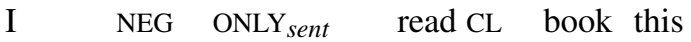

'I didn't only read [this] $]_{F}$ book.' $\Rightarrow$ I read (some) other books as well.

The two positions of $c h i$ in (27) also correspond to different meanings, as noted in (17) above. This suggests an alternative account for examples such as (25) with the full $\mathrm{CP}$ embedding and (27) with negation: perhaps sentential focus particles must be as low as possible, unless being higher yields a different interpretation.

The idea that a certain operation cannot take place unless it leads to a different semantics is not new. For example, Fox (1995, 2000) proposes that covert scope-shifting operations such as QR and scope reconstruction are subject to such a semantically-sensitive requirement. This principle is called Scope Economy: 
(28) Scope Economy (Fox, 2000):

Scope-shifting operations cannot be semantically vacuous.

For our purposes, this alternative revision to generalization (20) is stated in (29):

(29) A semantically-sensitive revision to generalization (20):

Sentential focus particles (focus-sensitive sentential modifiers) must be as low as possible while c-commanding their focus associate and deriving the intended truth conditions.

In the simple case of the examples in (25), repeated below as (30), this semantically-sensitive characterization in (29) will capture the relevant contrasts. Examples (30a-b) are both grammatical, even though chi is in a lower position in (30b) than in (30a), because they yield distinct truth conditions. However, note that placing chi higher, in matrix pre-subject position (30c), will yield the same truth conditions as (30b). (30c) therefore violates (29) and is ungrammatical.

(30) Matrix and embedded positions for $c h i$, given embedded focus, repeated from (25):
a. Tôi chỉ nói [cP là Nam thích $[\mathrm{Ngân}]_{\mathrm{F}}$ (thôi).
I ONLY sent $_{\text {say that Nam like Ngan PRT }}$
'I only said Nam likes $[\mathrm{Ngan}]_{\mathrm{F}}$.'
only $>$ say
I say that Nam ONLY sent like Ngan PRT
'I said Nam only likes [Ngan $]_{F}$.'
b. Tôi nói [cP là Nam chỉ thích $[\mathrm{Ngân}]_{\mathrm{F}}$ (thôi).
say $>$ only
c. * Chỉ tôi nói [CP là Nam thích [Ngân $]_{\mathrm{F}}$ (thôi).

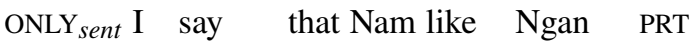
Intended: 'I only said Nam likes [Ngan $]_{F}$ ' (=a)

It can be shown, however, that the semantically-sensitive approach in (29) overgenerates in a way that the non-semantically-sensitive, purely syntactic statement in (20) does not. This argument will come from simplex clauses involving quantificational subjects. A baseline of this form is in (31) below. Here I will use a subject universal quantifier. Universal quantifiers in Vietnamese can be formed using a preverbal wh-word (here, $a i$ 'who') together with an 'also' operator cũng (Bruening and Tran 2006; Nguyen 2013). ${ }^{14}$ I note first that example (31) must be interpreted with the subject universal quantifier taking scope over ONLY, i.e. that Vietnamese is scope-rigid for relevant purposes.

\footnotetext{
14 See Kratzer and Shimoyama (2002); Shimoyama (2006) for discussion of, and a compositional semantics for, a similar combination of wh-phrases and an 'also' operator to express universal quantification in Japanese. See also Tran and Bruening (2013) on the semantics of Vietnamese wh-words.
} 


\section{(31) Subject quantifier baseline:}

Ai cũng chỉ mua [cuốn sách $]_{F}$. who also ONLY buy CL book

$\checkmark$ 'Everyone only bought [the book] F.'

* 'The book is the only thing that everyone bought.'

every $>$ only

*only $>$ every

Chi in (31) is in the lowest position possible while c-commanding its focus associate, and is predicted to be grammatical under both the purely syntactic generalization in (20) as well as the semantically-sensitive proposal in (29).

The test case is what happens if chi is adjoined above the quantificational subject and continues to associate with 'the book.' Semantically, the alternatives introduced by the F-marked object below will project to the complement of chi, with the universal quantifier composing pointwise with each alternative. We predict this structure to be interpretable, yielding a different reading with only > every scope: the book is the only thing that everyone bought. However, this sentence is ungrammatical with the intended reading.

\section{(32) Chi cannot be higher, even if it would lead to a different reading:}

* Chi ai cũng mua [cuốn sách $]_{\mathrm{F}}$.

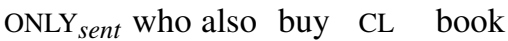

Int. 'Only [the book $]_{\mathrm{F}}$ is such that ${ }_{i}$ everyone bought $\mathrm{it}_{i}$.' only $>$ every

The intended meaning in (32) can of course be expressed, but it requires fronting the focus associate to a position above the quantificational subject.

\section{(33) Fronting can be used to force chi to scope higher, above every:}

$$
\begin{aligned}
& \checkmark \text { Chỉ (mối) } \quad \text { [cuốn sách }]_{\mathrm{F}} \text { ai cũng (mới) mua } \\
& \text { ONLY }_{\text {sent }} \text { ONLY }_{\text {cons }} \text { CL book who also PRT buy } \\
& \approx \text { 'Only [the book }]_{\mathrm{F}} \text { is such that }{ }_{i} \text { everyone bought it }{ }_{i} .
\end{aligned}
$$

Under the semantically-sensitive formulation in (29), the high placement of chi associating down with 'the book' (32) is predicted to be possible. Even though chi can be adjoined lower in the clause as in (31) and c-command its focus associate, the structure in (32) should yield a distinct truth-condition. The fact that (32) is nonetheless ungrammatical, then, shows that the generalization in (29) cannot be correct. That is, the "at low as possible" behavior observed in Vietnamese cannot be the result of a semantically-sensitive condition. In contrast, the purely syntactic formulation of the generalization in (20) above correctly predicts the ungrammaticality of (32). The fact that (32) should yield a different semantics is immaterial to this process which determines the position of sentential focus particles.

To conclude, in this section I presented data that motivates the view that the sentential 'only' chi in Vietnamese is always as low as possible in its phase while c-commanding its focus associate (20). This generalization correctly accounts for the (un)availability of chi in various positions with different associates, in all data presented here. 


\section{Focus particles and derivation by phase}

In this section I present my formal proposal for the distribution of focus particles in Vietnamese, which derives the empirical generalization documented in the previous section. This generalization in (20) is repeated below in (34). I will show that the distribution of Vietnamese sentential 'only' chi is best explained by-and in turn supports - the cyclic derivation of syntactic structure by phase, as envisioned by Chomsky (2000, 2001).

\section{(34) Generalization, repeated from (20):}

Sentential focus particles (focus-sensitive sentential modifiers) must be as low as possible while c-commanding their focus associate, within a given phase.

As discussed in Sect. 2.1, focus-sensitive operators are subject to a c-command requirement, whereby operators must c-command their intended focus associates. This explains the c-command requirement that is a part of (34). However, the semantics of association with focus itself is insensitive to syntactic locality (Rooth 1985), and therefore the requirements in (34) that sentential focus particles be adjoined as low as possible and that this requirement be relativized to each phase are not explained by the semantics of these particles alone. Furthermore, I showed that these effects do not reflect a semantically-sensitive condition which allows higher focus particle placement if it leads to a different semantics. The behavior observed shows us that there is a hard syntactic constraint governing the adjunction positions of these particles, not just requirements of semantic interpretation (cf Ernst 2002).

I propose that the behavior observed reflects a general principle governing local derivational choices. I will begin with a presentation of the relevant theoretical background, by way of discussion of a similar and well-studied principle, Merge over Move. Consider the examples in (35) from Chomsky (2000). These two examples differ in where the expletive there is introduced and how far we move a proof.

A motivation for Merge over Move: (based on Chomsky 2000, p. 104) ${ }^{15}$

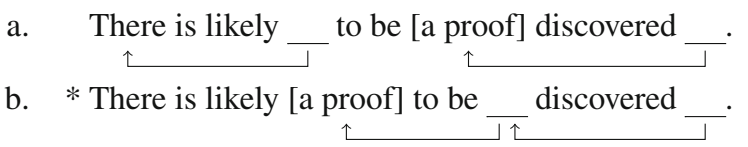

Following the construction of the embedded "to be a proof discovered," we must satisfy the EPP requirement of this embedded T head. The contrast in (35) shows that Merge of the expletive there to satisfy this EPP requirement is preferable to further movement of a proof, blocking the derivation in (35b) where the expletive is instead Merged only at the very last step, in order to satisfy the EPP requirement

\footnotetext{
15 The fact that the passive VP surfaces in (35b) as a proof discovered, rather than discovered a proof with $a$ proof in its base position, is attributed to a separate, language-specific process, dubbed the "thematization/extraction rule" in Chomsky (2001, p. 20). This is the source of the first/lowest movement step of a proof in both structures in (35) and in (36) below.
} 
of matrix T. Chomsky attributes this and similar contrasts to a general Merge over Move principle.

It's important to note that the movement of a proof to the edge of the embedded nonfinite TP in (35b) is not independently ruled out, as reflected by the grammatical derivation of (36). The availability of (36) reflects a derivation where a proof moves all the way up to satisfy the EPP feature on matrix T and the expletive there is never inserted.

$$
\text { [A proof] is likely } \frac{\varsigma}{\downarrow \uparrow} \text { to be } \frac{\tau}{\downarrow \downarrow} \text { discovered } \_ \text {. }
$$

The availability of both (35a) and (36) is explained by the important notion of the lexical array in the Minimalist Program. As outlined in Chomsky (1995, et seq), derivations are constructed out of a set of lexical items which are first preselected from the lexicon, much as a prepared chef lays out all necessary ingredients before beginning to cook. This set of lexical items is called the lexical array, and it must be exhausted for convergence of the derivation. The derivation of (36) involves a lexical array that does not include the expletive there, whereas (35a) is built from a lexical array that differs minimally in the addition of there. Example (35b) reflects another derivation using the same lexical array as for (35a), but violating Merge over Move.

Chomsky (2000) shows that there are cases where Merge over Move appears at first glance to not have taken effect, such as example (37):

(37) Merge over Move does not hold over the entire structure: (based on Chomsky 2000, p. 103)

There is a possibility [ $\mathrm{CP}$ that [a proof] will be $\__{\downarrow}$ discovered $\_$] .

The derivation of (37) necessarily includes the expletive there in the lexical array. At the point where "will be a proof discovered" has been built and this embedded T's EPP feature must be satisfied, we might expect Merge over Move to predict that the expletive from the lexical array be Merged instead of moving the subject $a$ proof. However, the grammaticality of (37) shows that Merge over Move does not force the introduction of the expletive here. Chomsky takes examples of this form to motivate the idea that complex linguistic expressions can be built from a sequence of separate lexical subarrays, which each result in a phase (Chomsky 2000, p. 106ff). The lexical subarray for the embedded clause in (37) does not include the expletive there and therefore Merge over Move does not block the derivation in (37). Merge over Move holds in (35) because embedded nonfinite TP and passive $v$ Ps are not phases, ${ }^{16}$ in contrast to the $\mathrm{CP}$ embedding in (37).

These independently motivated and widely-adopted assumptions of Chomsky's Minimalist Program - constraints on local derivational choices such as Merge over Move and their applicability only within individual phases-offer a very natural explanation for the distribution of focus particles observed here. I propose that the

16 The idea that passive and unaccusative $v$ Ps are not full-fledged phases has since been controversial; see e.g. Legate (2003). This issue is not relevant for our discussion. 
behavior observed, generalized in (34) above, reflects the following general principle: ${ }^{17}$

\section{(38) Adjoin As Soon As Possible: ${ }^{18}$}

Adjuncts should be adjoined as soon as they will be interpretable. ${ }^{19}$

Because focus particles are adjuncts, there are many points in the derivation where we could choose to Merge in a focus particle from the lexical array. ${ }^{20}$ The principle in (38) says that this adjunction should take place as soon as possible. Because only lexical items from the current lexical subarray (ingredients for the current phase) can be considered at a time, this derives the observed "as low as possible" behavior which is relativized to the phase.

Let's see how the idea of derivation by phase and Adjoin As Soon As Possible (38) together correctly derive the distribution of the Vietnamese sentential 'only' chi observed here. I begin by constructing the lower phase of the clause, VP, in (39). Note that details that are orthogonal to the issue of focus particle placement are simplified here. For example, as noted in footnote 4 above, I do not distinguish between $v \mathrm{P}$ and VP here. Using the items in the lexical subarray $\mathrm{LA}_{1}$-including the output of an earlier DP phase subderivation - the VP phase is formed.

17 Radek Šimík (p.c.) notes that Hagstrom (1998, p. 185) entertains a principle, dubbed "Avoid Flexible Functional Application," which similarly encourages focus-sensitive operators to merge low, specifically in the domain of wh-question interpretation.

18 "As soon as possible" here assumes a bottom-up structure-building process. In a model of left-to-right or top-down structure-building, the principle would be restated as Adjoin As Late As Possible.

19 In the case of focus particles, "being interpretable" here translates into the c-command requirement on focus particles: focus particles must c-command their intended focus associate (6). This can be further formalized without recourse to lookahead in one of at least two ways:

1. The "intended associate" can be checked by adopting the view that F-marked constituents bear a focus index $\mathrm{F}_{i}$ (Kratzer 1991; Wold 1996; Erlewine 2014). If the complement of the focus particle is a constant function across different assignments for the relevant focus-index, we know immediately that the focus particle's semantics will be unsatisfied.

2. Here I have followed the common Roothian assumption that focused constituents are interpreted in-situ at LF (Rooth 1985, a.o.). However, an alternative would be to require that the focus particle Agree with and Attract its intended associate for covert movement (see e.g. Chomsky 1976; Drubig 1994; Krifka 2006; Wagner 2006; Erlewine and Kotek 2014, 2016, to appear). In this case, if the intended associate is not in the complement of the focus particle, the derivation will crash. See Erlewine (2015) for discussion of the derivation of the generalization in (34) using covert focus movement.

20 I take adjunction to be the free Merge of two syntactic objects which each have no remaining selectional or probing features; e.g. maximal projections. See also footnote 13 above.

Works such as Cinque (1999) have observed that many adverbs have specific positions in the clause where they prefer to or must adjoin. Such restrictions are in principle compatible with the principle I propose in (38): the effect of (38) will simply only be observed with adjuncts which have multiple possible positions for adjunction with the phase. As I have shown, Vietnamese sentential focus particles are not required to adjoin to a particular fixed position in the clause, allowing us to see the effects of (38) on their distribution. 


\section{(39) Derivation of a VP phase with object focus:}
a. $\mathrm{LA}_{1}=\left\{\right.$ buy, $\left.[\mathrm{DP} \text { CL book }]_{\mathrm{F}}\right\}$
b. [vP buy DP ]

Now consider the derivation of the $\mathrm{CP}$ phase in (40). The lexical subarray $\mathrm{LA}_{2}$ includes the functional heads $\mathrm{C}$ and $\mathrm{T}$, the lower VP phase from (39), a subject DP $N a m,{ }^{21}$ and the sentential 'only' chi. I enumerate the derivational steps taken and their results in $(40 \mathrm{~b})$.

(40) Derivation of the CP phase, following (39):

a. $\mathrm{LA}_{2}=\left\{\mathrm{C}, \mathrm{T}, \mathrm{VP}(39), \mathrm{ONLY}_{\text {sent }},[\mathrm{DP}\right.$ Nam] $\}$

b. i. Adjoin ONLY sent to VP [VP ONLY sent VP]

ii. Merge $\mathrm{T}$ and (i)

[ $\left.\mathrm{T}\left[\mathrm{VP} \mathrm{ONLY}_{\text {sent }} \mathrm{VP}\right]\right]$

iii. Merge subject with (ii) $\quad$ [TP DP [ T [VP $\left.\left.\left.\mathrm{ONLY}_{\text {sent }} \mathrm{VP}\right]\right]\right]$

iv. Merge $\mathrm{C}$ with (iii)

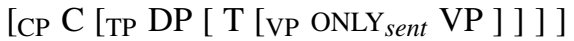

The derivation in (40) begins with the adjunction of 'only' because 'only' will c-command its associate ('the book') from this position and will be interpretable, and therefore Adjoin As Soon As Possible (38) requires that we adjoin immediately at this point. This results in the correct word order: chi is in immediately preverbal position. Adjoining chi in at a later stage-for example, after the construction of the $\mathrm{TP}$-is generally possible syntactically and would be an interpretable structure, but violates the Adjoin As Soon As Possible principle, and is therefore ruled out.

In contrast, suppose that F-marking is on the subject Nam instead. Following the construction of the VP which contains no F-marking, in (41), we build the CP phase in (42).

(41) Derivation of a VP phase with no focus:

a. $\mathrm{LA}_{1}=\{$ buy, $[\mathrm{DP}$ CL book $]\}$

b. [vP buy DP ]

(42) Derivation of the CP phase with subject focus:

a. $\mathrm{LA}_{2}=\left\{\mathrm{C}, \mathrm{T}, \mathrm{VP}(41), \mathrm{ONLY}_{\text {sent }},[\mathrm{DP} \mathrm{Nam}]_{\mathrm{F}}\right\}$

b. i. Merge T and VP [ T VP ]

ii. Merge subject with (i) [TP DP [ T VP ] ]

iii. Adjoin $\mathrm{ONLY}_{\text {sent }}$ to TP (ii) [TP $\mathrm{ONLY}_{\text {sent }}[\mathrm{TP} \mathrm{DP}$ [ T VP ] ] ]

iv. Merge C with (iii) $\quad$ [CP C [

In the derivation of (42), we cannot adjoin 'only' in the first step as we did in (40), because 'only' will not c-command its associate Nam here and will therefore not

21 For simplicity, I do not assume a VP-internal base position for subjects. See footnote 22 below. 
be interpretable. ${ }^{22}$ We therefore must wait to adjoin until after the F-marked subject Nam has been inserted, so that ONLY will c-command it. The sentential 'only' $c h i$ will therefore occur higher in the clause in this example, even though this higher placement is ungrammatical with a lower focus as in (40).

The higher and lower adjunction points for 'only' in the examples discussed here block one another, because 'only' in both (40) and (42) are introduced in the same lexical subarray: the lexical subarray for the CP phase in a simplex clause. If we instead build a complex clause with multiple phases where 'only' can be included as an ingredient, the one adjunction option will not block the other.

Consider the examples of embedded object focus below, taken from (25) above, with phases labeled:

\section{(43) Matrix and embedded positions for chi, given embedded focus,} from (25):
a. [CP1 Tôi chỉ
I ONLY sent $_{\text {sen }}$
'I only said Nam likes [Ngan $]_{F}$.'
[VP1 nói [CP2 là Nam [VP2 thích [Ngân $]_{F}$.
b. [CP1 Tôi [VP1 nói [CP2 là Nam chỉ [VP2 thích [Ngân $]_{F}$. I say that Nam ONLY sent like Ngan
'I said Nam only likes [Ngan $]_{F}$.'

The availability of both examples in (43) reflects the choice of selecting the sentential 'only' in the lexical subarray for the higher CP, CP1, or the lower CP, CP2. ${ }^{23}$ In each clause where 'only' must be used, its adjunction will be subject to the Adjoin As Early As Possible principle. In this case, in both CP1 and CP2, if 'only' is in the lexical subarray, it will adjoin immediately as it then c-commands its intended focus associate and is interpretable. The proposal here successfully models the distribution of the sentential focus particle chi as documented here.

\footnotetext{
22 This raises an important question regarding VP-internal subjects. If the VP-internal subject hypothesis is adopted for Vietnamese, the intended associate of 'only' will be inside the lower phase, and therefore we may expect Adjoin As Soon As Possible to require immediate adjunction, just as it did in (40). Subsequent raising of the subject to Spec,TP will however bleed focus association, because 'only' cannot associate with a focused constituent which has moved out of its scope (Erlewine 2014).

I believe the correct response is to take such details to motivate a view where the "as low as possible" requirement is used to compare related derivations which converge based on a fixed input lexical array. This is reminiscent of transderivational competition between derivations in a "reference set" in early Minimalist work (e.g. Chomsky 1995). Choosing the optimal derivation cyclically, at the end of each phase (Heck and Müller 2001; Fanselow and Ćavar 2001), would derive the desired effects. This transderivational approach is discussed in Erlewine (2015).

23 Sentential focus particles generally cannot successfully be included in the construction of a VP phase, as their semantics quantifies over propositional alternatives and therefore they must adjoin to a node of propositional type. The VP phase is propositional given the VP-internal subject hypothesis; see footnote 22 above. An exception is if the construction of a VP itself includes a propositional node such as a lower VP as a subpart. This explains the availability of lower chi adjunction under the negative verb không as discussed in (27) above.
} 


\section{Conclusion}

In this paper I described the distribution of exclusive focus particles in Vietnamese. Building on previous descriptive work in Hole (2013), I showed that the focus particle chi is consistently a sentential 'only,' adjoining to the clausal spine above the verb, and cannot be adjoined to other categories as the constituent 'only' mối can. The semantics of 'only' predicts that chi should then be able to associate with any focus in its c-command domain, from any adjunction position. Instead, we observe that the distribution of $c h i$ is limited, following the generalization repeated here:

(44) Generalization, repeated from (20):

Sentential focus particles (focus-sensitive sentential modifiers) must be as low as possible while c-commanding their focus associate, within a given phase.

This work shows the necessity of syntactic constraints on adjunct placement, such as the principle Adjoin As Early As Possible that I proposed in Sect. 4, repeated here:

(45) Adjoin As Soon As Possible: (=38)

Adjuncts should be adjoined as soon as they will be interpretable.

This principle in (45) is a principle governing local derivational choices just as Chomsky's Merge over Move does, and its effects are similarly observed only within individual phases. This is an immediate consequence of the theory of derivation by phase in Chomsky $(2000,2001)$.

The existence of effects such as what I observe for the distribution of Vietnamese chi and its sensitivity to phase boundaries forms a new argument for the phase-byphase cyclic nature of syntactic structure-building. In future work, the boundaries of such "as low as possible" effects could be used as a new empirical diagnostic for phasehood. This consequence highlights the cross-linguistic study of the distribution of focus particles as a potentially significant area of study.

By way of conclusion, I return to the fact, noted in passing above, that the generalization here in (44) is similar to what has been proposed for German focus particles by Jacobs (1983, 1986) and Büring and Hartmann (2001). Consider the position of nur 'only' associating with 'novel' in (46) below. Given the head-final structure of German clauses, we can imagine two possible parses: nur could be a sentential 'only' adjoined to a (extended) VP (46a) or could be adjoined directly to the DP containing focus (46b).

(46) Two hypotheses for German focus operators: (Büring and Hartmann 2001) Ich habe nur einen ROMAN gelesen.

I have ONLY a novel read

'I read only a [novel $]_{\mathrm{F}}$.'

a. Nur as sentential 'only':

Ich habe [vP nur [VP [DP einen [Roman] $]_{\mathrm{F}}$ gelesen]] 


\section{b. Nur as constituent 'only': \\ Ich habe [VP [DP nur [DP einen [Roman] $\left.]_{\mathrm{F}}\right]$ gelesen]}

Jacobs (1983, 1986) and Büring and Hartmann (2001) take the strong position that German focus particles are always sentential modifiers, but then must propose a constraint akin to the generalization in (44) above. Büring and Hartmann (2001) calls this a Closeness constraint.

(47) Closeness: (Büring and Hartmann 2001, p. 237)

Focus-sensitive adverbs are as close to the focus associate as possible.

In later discussion, Büring and Hartmann (2001) take Closeness to only apply between different adjunction sites on the same extended (verbal) projection, which comes very close to the generalization we reach here based on Vietnamese data. ${ }^{24}$ I believe the proposal here based on Adjoin As Early As Possible applying during the derivation of each phase is able to derive the Closeness behavior in German, if it is assumed, with Jacobs (1983, 1986) and Büring and Hartmann (2001), that focus particles in German are indeed always sentential modifiers.

This assumption is however highly controversial. Consider for example the interaction of focus particles with the well-known verb-second (V2) property of German syntax. In V2 clauses such as main clauses, exactly one constituent must occupy the preverbal, "prefield" position. It turns out that focus particles can precede a focused constituent in prefield position, though, as in example (48). If nur can adjoin to Hans as a constituent 'only,' the verb-second generalization is maintained. However, under the hypothesis of Jacobs and Büring and Hartmann that all German focus particles are sentential modifiers, we are required to analyze such examples as exceptional instances of verb-third.

\section{(48) Focus particles require V3?}

Nur [Hans $]_{F}$ war betrunken.

ONLY Hans was drunk

'Only [Hans $]_{F}$ was drunk.'

For this and a number of other reasons, the Jacobs/Büring and Hartmann position remains controversial. See in particular Reis (2005); Meyer and Sauerland (2009); Smeets and Wagner (2016) for a series of additional arguments against their sentential-only view. Given the apparent imperfections of this approach, the otherwise sui generis Closeness constraint (47) which Jacobs and Büring and Hartmann must maintain has itself been criticized as unmotivated.

On the contrary, I have shown here that such an "as low as possible" generalization on sentential focus particles is alive and well in Vietnamese. In contrast to German; where a focus particle such as nur may-for example if Reis (2005) is correct-be ambiguous between a sentential 'only' and constituent 'only, just as English only is, in Vietnamese we can clearly identify the exclusive particle $c h i$ as being a sentential

\footnotetext{
24 In Erlewine (in progress), I show that such "as low as possible" effects are also observed in Mandarin Chinese.
} 
'only' in contrast to the constituent 'only' mối, making for a clearer exemplar of such an "as low as possible" effect. This shows that the Closeness behavior described by Büring and Hartmann (2001)—described as potentially "spurious" and "more than doubtful" by Reis (2005) - is an independently necessary possibility in natural language. The discovery of this same pattern across genetically unrelated languages is a striking example of the null hypothesis of Universal Grammar, that even genetically unrelated languages will exhibit reflexes of an underlyingly universal computational system.

Acknowledgments For judgments and discussion of data, I thank Trang Đặng, Anne Nguyen, Nguyễn Hữu Cát Thư, Chieu Nguyen, and Trần Thị Hương Giang. For further comments and discussion, I especially thank Noah Constant, Martin Hackl, Irene Heim, James Huang, Tim Hunter, Hadas Kotek, Waltraud Paul, David Pesetsky, Yosuke Sato, Radek Šimík, Luis Vicente, Michael Wagner, Malte Zimmermann, anonymous reviewers, and audiences at Theoretical East Asian Linguistics 9, NELS 45, and the 2015 LSA, as well as at the following institutions: the Universities of Leipzig, Minnesota, Potsdam, and Washington; Concordia and McGill Universities; Swarthmore College; MIT; and the National University of Singapore. Errors are mine.

Open Access This article is distributed under the terms of the Creative Commons Attribution 4.0 International License (http://creativecommons.org/licenses/by/4.0/), which permits unrestricted use, distribution, and reproduction in any medium, provided you give appropriate credit to the original author(s) and the source, provide a link to the Creative Commons license, and indicate if changes were made.

\section{References}

Aoun, Joseph, and Yen-hui Audrey Li. 1993. Wh-elements in situ: Syntax or LF? Linguistic Inquiry 24: 199-238.

Bayer, Josef. 1996. Directionality and logical form: On the scope of focusing particles and wh-in-situ. Berlin: Kluwer Academic Publishers.

Beaver, David Ian, and Brady Clark. 2008. Sense and sensitivity: How focus determines meaning. Hoboken: Wiley.

Bruening, Benjamin, and Thuan Tran. 2006. Wh-questions in Vietnamese. Journal of East Asian Linguistics 15: 319-341.

Büring, Daniel, and Katharina Hartmann. 2001. The syntax and semantics of focus-sensitive particles in German. Natural Language \& Linguistic Theory 19: 229-281.

Chomsky, Noam. 1976. Conditions on rules of grammar. Linguistic Analysis 2: 303-350.

Chomsky, Noam. 1995. The minimalist program. Cambridge: MIT Press.

Chomsky, Noam. 2000. Minimalist inquiries: The framework. In Step by step: Essays on minimalist syntax in honor of Howard Lasnik, ed. Roger Martin, David Michaels, and Juan Uriagereka, 89-156. Cambridge: MIT Press.

Chomsky, Noam. 2001. Derivation by phase. In Ken Hale: A life in language, ed. Michael Kenstowicz, 1-52. Cambridge: MIT Press.

Cinque, Guglielmo. 1999. Adverbs and functional heads. Oxford: Oxford University Press.

Drubig, Hans Bernhard. 1994. Island constraints and the syntactic nature of focus and association with focus. Arbeitspapiere des Sonderforschungsbereichs 340: Sprachtheoretische Grundlagen der Computerlinguistik 51 .

Erlewine, Michael Yoshitaka. 2014. Movement out of focus. Doctoral Dissertation, Massachusetts Institute of Technology.

Erlewine, Michael Yoshitaka. 2015. Minimality and focus-sensitive adverb placement. In Proceedings of NELS 45, ed. Thuy Bui and Deniz Özyildiz, vol. 1, 193-202.

Erlewine, Michael Yoshitaka. in progress. The uniform syntax of Mandarin Chinese focus particles.

Erlewine, Michael Yoshitaka, and Hadas Kotek. 2014. Intervention in focus pied-piping. In Proceedings of NELS 43, ed. Hsin-Lun Huang, Ethan Poole, and Amanda Rysling, vol. 1, 117-130. 
Erlewine, Michael Yoshitaka, and Hadas Kotek. 2016. Tanglewood untangled. In Proceedings of SALT 26, ed. Mary Moroney, Carol-Rose Little, Jacob Collard, and Dan Burgdorf, 224-243.

Erlewine, Michael Yoshitaka, and Hadas Kotek. to appear. Focus association by movement: Evidence from Tanglewood. In Linguistic Inquiry.

Ernst, Thomas. 2002. The syntax of adjuncts. Cambridge: Cambridge University Press.

Fanselow, Gisbert, and Damir Ćavar. 2001. Remarks on the economy of pronunciation. In Competition in syntax, ed. Gereon Müller, and Wolfgang Sternefeld, 107-150. Berlin: Walter de Gruyter.

Fox, Danny. 1995. Economy and scope. Natural Language Semantics 3: 283-341.

Fox, Danny. 2000. Economy and semantic interpretation: A study of scope and variable binding. Cambridge: MIT Press.

Guimarães, Maximiliano. 2004. Derivation and representation of syntactic amalgams. Doctoral Dissertation, University of Maryland.

Hagstrom, Paul. 1998. Decomposing questions. Doctoral Dissertation, Massachusetts Institute of Technology.

Heck, Fabian, and Gereon Müller. 2001. Successive cyclicity, long-distance superiority, and local optimization. In Proceedings of WCCFL 19, ed. Roger Billerey and Brook Danielle Lillehaugen, 218-231.

Hole, Daniel. 2013. Focus particles and related entities in Vietnamese. In Linguistics of Vietnamese: An international survey, ed. Daniel Hole, and Elisabeth Löbel, 265-303. Berlin: De Gruyter.

Hole, Daniel. 2014. The scalar basis of (Vietnamese) focus particle doubling. Presented at the 9th Workshop on Theoretical East Asian Linguistics (TEAL 9), University of Nantes.

Jackendoff, Ray. 1972. Semantic interpretation in generative grammar. Cambridge: MIT Press.

Jacobs, Joachim. 1983. Fokus und Skalen: Zur Syntax und Semantik der Gradpartikeln im Deutschen. Tübingen: Niemeyer.

Jacobs, Joachim. 1986. The syntax of focus and adverbials in German. In Topic, focus, and configurationality, ed. Werner Abraham, and Sjaak de Meij, 103-128. Amsterdam: John Benjamins.

Jannedy, Stephanie. 2007. Prosodic focus in Vietnamese. In Interdisciplinary studies on information structure 8, ed. Shinichiro Ishihara, Stephanie Jannedy, and Anne Schwarz, 209-230. Potsdam: University of Potsdam.

Kadmon, Nirit. 2001. Formal pragmatics. Oxford: Blackwell.

Kluck, Marlies. 2011. Sentence amalgamation. Doctoral Dissertation, University of Groningen.

Kratzer, Angelika. 1991. The representation of focus. In Semantik: Ein internationales handbuch der zeitgenössischen forschung, ed. Arnim von Stechow, and Dieter Wunderlich, 825-834. Berlin: Walter de Gruyter.

Kratzer, Angelika, and Junko Shimoyama. 2002. Indeterminate pronouns: The view from Japanese. In The Proceedings of the Third Tokyo Conference on Psycholinguistics (TCP 2002), ed. Yuko Otsuka, 1-25. Tokyo: Hitsuji Syobo.

Krifka, Manfred. 1998. Additive particles under stress. In Proceedings of SALT 8, ed. Devon Strolovitch, and Aaron Lawson, 111-129. Ithaca: Cornell University.

Krifka, Manfred. 2006. Association with focus phrases. In The architecture of focus, ed. Valéria Molnár, and Susanne Winkler, 105-136. Berlin: Mouton de Gruyter.

Lakoff, George. 1974. Syntactic amalgams. In Proceedings of CLS 10, 321-344.

Legate, Julie Anne. 2003. Some interface properties of the phase. Linguistic Inquiry 34: 506-515.

McCawley, James D. 1996. The focus and scope of only. In Discourse and meaning: Papers in honor of Eva Hajicová, ed. Barbara Hall Partee, and Petr Sgall, 171-193. Amsterdam: John Benjamins.

Meyer, Marie-Christine, and Uli Sauerland. 2009. A pragmatic constraint on ambiguity detection. Natural Language \& Linguistic Theory 27: 139-150.

Nguyen, Chieu. 2013. Fusion and scattering in particle collisions: When universal quantification and contrastive focus interact with themselves and each other in Vietnamese. In Proceedings of GLOW in Asia IX, ed. Nobu Goto, Koichi Otaki, Atsushi Sato, and Kensuke Takita, 213-228.

Reis, Marga. 2005. On the syntax of so-called focus particles in German: A reply to Büring and Hartmann 2001. Natural Language \& Linguistic Theory 23: 459-483.

Rooth, Mats. 1985. Association with focus. Doctoral Dissertation, University of Massachusetts, Amherst.

Rooth, Mats. 1992. A theory of focus interpretation. Natural Language Semantics 1: 75-116.

Shimoyama, Junko. 2006. Indeterminate quantification in Japanese. Natural Language Semantics 14: 139173. 
Smeets, Liz, and Michael Wagner. 2016. The syntax of focus association in Dutch and German: Evidence from scope reconstruction. In Proceedings of WCCFL 34, ed. Aaron Kaplan, Abby Kaplan, Miranda K. McCarvel, and Edward J. Rubin, 470-480.

Taglicht, Josef. 1984. Message and emphasis: On focus and scope in English. Harlow: Longman.

Tancredi, Chris. 1990. Not only EVEN, but even ONLY. Manuscript, Massachusetts Institute of Technology. Tran, Thuan, and Benjamin Bruening. 2013. Wh-phrases as indefinites: A Vietnamese perspective. In Linguistics of Vietnamese: An international survey, ed. Daniel Hole, and Elisabeth Löbel, 217-241. Berlin: De Gruyter.

Trinh, Tue. 2005. Aspects of clause structure in Vietnamese. Master's thesis, Humboldt University.

Wagner, Michael. 2006. Association by movement: Evidence from NPI-licensing. Natural Language Semantics 14: 297-324.

Wagner, Michael. 2013. Additivity and the syntax of even. Montreal: McGill University.

Wold, Dag E. 1996. Long-distance selective binding: The case of focus. In Proceedings of SALT 6, ed. Teresa Galloway and Justin Spence, 311-328. 